\title{
Adölesan Gebelikler
}

\section{Adolescent Pregnancy}

\begin{abstract}
Ayça ŞOLT $^{\mathrm{a}} \quad$ Saadet YAZICI $^{\mathrm{b}}$
Özet Adölesan dönem, geniş anlamıyla bireyin biyolojik, psikolojik ve sosyal değişimlerle birlikte çocukluktan yetişkinliğe geçiş dönemi olarak tanımlanır. Dünya nüfusunun \%30'nu oluşturan adölesanların \%90'nı gelişmekte olan ülkelerde yaşamaktadır. Dünyada her yıl yapılan doğumların yaklaşı \%11’i 15-19 yaş grubunda yer alan adölesan kızlar tarafindan yapılmaktadır. Ülkemizde ise 15-19 yaş arasındaki adölesanların \%16'sı evli olup, 19 yaşından sonra \%16'sı annedir ya da ilk çocuğuna gebedir. Yapılan çalışmalar adölesan gebeliklerin oluşmasında, eğitim, iş, sosyo-ekonomik ve evlilik durumu, aile planlaması yöntemleri konusunda bilgi yetersizliği, okul ve aile tarafindan cinsel sağlık/ üreme sağlığı konusunda yeterli bilginin verilmemesi etkili olmaktadır. Adölesan gebeliğin risk faktörleri çok yönlü ve karmaşıktır. Düşük, erken doğum, düşük doğum ağırlığı, preeklampsi-eklampsi, anemi, uzamış doğum eylemi, erken memran rüptürü, müdahaleli doğum, fistül oluşumu, yetersiz doğum öncesi bakım alma, madde kullanımı, cinsel yolla bulaşan hastalık riski bunlar arasındadır. Adölesan gebeliklerin önlenmesi için cinsel sağlı/üreme sağlı̆̆ hizmetlerinin yaygınlaştırılması, adölesan poliklinikleri oluşturulması ve adölesanlara yönelik eğitim programları hazırlanması ve kitle iletişim araçlarının kullanılması gerekir.
\end{abstract}

Anahtar kelimeler: Adölesan dönem, gebelik, adölesan gebelik, risk faktörleri

\begin{abstract}
Adolescence term is widely described as a period in which an individual transfers form childhood to adulthood experiencing some biological, psychological and social changes. $\% 90$ of adolescents who account for $\% 30$ of the World population live in developing countries. Nearly \% 11 of all the births in the World are given by female adolescents between 15 and 19 every year. In our country $\% 16$ of adolescents who are between 15-19 are married.\%16 of those who are over 19 are mothers or pregnant with their first child. Studies suggest that adolescent pregnancies are resulted from lack of education, en employment, lower socio-economic status, marrital status, shortage of knowledge about birth-control methods and insufficient information on fertility and sexual heath coming from families and schools. The risk factors of adolescent pregnancy are multiple and complex. Among the factors are abortion, pre-term labour, low birth-rate, pre-eclampsia, eclampsia, anemia, prolonged labour, prematüre rupture of membrane, fistüle, unadequate antenatal care, substance-use, sexuallytransmitted disease. In order to prevent adoloscence pregnancies, it is necessarry to spread the sexual health service, open the polyclinics for adolescents, prepare education programmes for adolescents and use the messmedia effectively to inform them.
\end{abstract}

Keywords: Adolescent term, pregnancy, Adolescent pregnancy, the risk factors

Geliş Tarihi/Recevied: 12.02.2015 Kabul Tarihi/Accepted:21.04.2015

a aycasolt@hotmail.com, aycasolt@gmail.com,Bahçelievler 11 Nolu Aile Sağlı̆̆ı Merkezi, Adnan Kahveci Bulvarı No:45/1 34182, Bahçelievler/İstanbul

${ }^{\text {b }}$ Yazıșma Adresi /Correspondence: Doç. Dr., İstanbul Üniversitesi Sağlık Bilimleri Fakültesi Ebelik Bölümü, saadetyazc@yahoo.com, Demirkapı Cad. Karabal Sok. Bakırköy Ruh ve Sinir Hastalıkları Hastanesi Bahçesi içi, 34740, Bakırköy/İstanbul 


\section{Giriş}

Adölesan dönemi, geniş anlamıyla bireyin biyolojik, psikolojik ve sosyal değişimlerle birlikte çocukluktan yetişkinliğe geçiş periyodu olarak tanımlanır. Dünya Sağlık Örgütü'nün (DSÖ) tanımına göre bu dönem 10-19 yaş arası olarak ifade edilmektedir. ${ }^{1-4}$ Bir çok anlamda özel bir dönem de olan adölesanlar dünya nüfusunun \%30'nu oluşturmakta ve \%90'nı gelişmekte olan ülkelerde yaşamaktadır. ${ }^{3,5,6}$

15-19 yaş grubunda yer alan 16 milyon adölesan k1z her y1l doğum yapmakta, bu doğumlar tüm dünya da yapılan doğumların yaklaşık \%11'lik bölümünü oluşturmakta ve $\% 95$ 'i gelişmekte olan ülkelerde olmaktadır. ${ }^{5}$ Günümüzde 18 yaşın altında her beş kız çocuğundan biri gelişmekte olan ülkelerdedir ve her üç kız çocuğundan biri doğum yapmaktadır., ${ }^{5,6}$ Gelişmiş ve gelişmekte olan ülkelerde adölesan doğumlar yaygın olarak görülmektedir. Adölesan doğum oranlarının Çin'de \%2, Latin Amerika'da ve Karayip'lerde \%18 ve Güney Afrika'da \%50'lerde olduğu görülmektedir. ${ }^{7}$ Gelişmiş ülkelerdeki adölesan doğum oranları da oldukça yüksek olup, İngiltere'de \%26, İrlanda'da \%17 ve Amerika Birleşik Devletleri'nde (ABD) 1990'11 y1llardan itibaren düşme eğilimi göstermesine rağmen bu oran $\% 63$ 'tür. ${ }^{8-10}$

Türkiye Nüfus ve Sağlık Araştırması (TNSA) 2013 verilerine göre; ülkemizde nüfusun \%26's1 adölesan yaş gurubu olup, 15-19 yaş arası adölesanların \%16'sı evli ve anne olma oranı yaşla birlikte hızla artmaktadır. Adölesan dönemde çocuk doğurmaya başlayanların yüzdesinin 18 yaşından sonra keskin bir şekilde arttığ görülmektedir. Çocuk doğurma davranışı 17 yaşından önce nadirdir, ancak 19 yaşındaki kadınların \%16'sı anne olmuş veya ilk çocuğuna gebedir. Bu sonuçlar TNSA 2008 sonuçları ile karşılaştırıldığında erken dönemde çocuk sahibi olmaya başlayan adölesanların oranında düşüş olduğu görülmektedir. $\mathrm{Bu}$ oran TNSA 2008 sonuçlarında \%6 iken, TNSA 2013 verilerine göre $\% 5$ 'e gerilemiştir. Adölesan dönemde çocuk sahibi olma ile kır-kent ve bölgeler arasında farklılık göstermektedir. Batı'da \%3 olan bu oran Güney, Orta ve Doğu'da \%6 veya daha fazladır. İlk evlenme yaşının doğumlar üzerinde önemli bir etkisi vardır. Erken yaşlarda evlenen kadınlar ortalama olarak daha uzun süre gebelik riski altına girmekte, bu da genellikle yaşam boyunca daha fazla sayıda doğum yapmaya neden olabilmektedir. ${ }^{11,12}$

Günümüzde hem gelişmiş hem de gelişmekte olan ülkelerin en önemli sağlık sorunlarından biri olan adölesan gebelikler hem anne hem de bebek sağlığını olumsuz etkilemektedir. Yüksek riskli gebelikler arasında yer alan adölesan gebelikler, anne ve bebek açısından önemli sosyal ve sağlık sorunlarına neden olabilmektedir. Gelir düzeyi düşük ve gelişmekte olan ülkelerde adölesanların \%30'u 18 yaşından, \%14'ü 15 yaşından önce evlenmektedir. Aynı zamanda 15-19 yaş arasındaki adölesanlar kendilerinden daha yaşlı erkek ile evliliğe ya da cinsel ilişkiye zorlanmaktadır., ${ }^{5,6}$ Latin Amerika gibi yüksek gelirli ülkelerde adölesanların evlilik dışı gebeliği yüksek oranda gözlenmektedir. ${ }^{6}$

Gebelik; biyolojik, psikolojik ve sosyal gelişimini tamamlamamış olan adölesanın eğitimini ve meslek sahibi olmasını engellemekte, ${ }^{13}$ ağır sorumluluklar yüklemekte ve resmi nikah yapılmasını engellemektedir. $^{12} \quad$ Melekoğlu ve arkadaşlarının (2013) çalışmasında adölesan kadınların \%52.5'nin resmi nikahı olmadı saptanmıştır. ${ }^{3}$

Eğitim süresinin artışıyla adölesan doğurganlık arasında güçlü bir ilişki vardır. ${ }^{6}$ TNSA 2013 verilerin göre eğitimi olmayan veya ilkokulu bitirmemiş kadınların \%17'si adölesan dönemde çocuk doğurmaya başlarken, bu oran en az ilkokulu bitirmiş kadınlar arasında \%8 düzeyindedir. Adölesan gebelikler eğitimsizlerde daha fazla görülürken, gebelik annelerin eğitimlerine devam etmelerine, çalışma yaşamına katılmasına engel olmakta ve genci ekonomik açıdan bağımlı hale getirmektedir. $^{12}$

Cabezon ve arkadaşlarının 2003 
yılında yaptıkları bir çalışma da devlet lisesinde ( 1996, 1997 ve 1998 y1lları arasında) okuyan 1259 kız öğrenciye gebe kalmayı önlemek için eğitim yapılmış. Yıllara göre ayrılan gruplarda, 1996 yılındaki grupta $425 \mathrm{kız}$ ögrenciye eğitim yapılmamış, 1997 yılındaki grupta yer alan 210 öğrenciye eğitim yapılmış, 213 öğrenciye eğitim yapılmamış ve 1998 yılındaki son grupta bulunan 328 öğrenciye eğitim yapılmış, 83 öğrenciye yapılmamıştır. Tüm gruplar 4 yll boyunca izlenmiş ve gebe kalma oranları eğitim alan gruplarda eğitim almayan gruplara göre oldukça düşük bulunmuștur. (\%3,3 ile \%18.9- \%4.4 ile $\% 22.6) .{ }^{14}$

Adölesan doğurganlık, sağlık ve sosyal sonuçları dikkate alındığında önemli bir sorun olarak ortaya çıkmaktadır. İlk gebelik için en uygun yaş olarak belirli bir görüş olmamasına rağmen psikolojik, obstetrik ve fizyolojik açıdan en uygun dönem 24-30 yaş arası kabul edilebilir. Adölesan gebeliklerde ağırlık değişiklikleri, toksemi, anemi, kişilik değişiklikleri, prematür doğum, perinatal mortalite, doğum öncesi yetersiz bakım alma ve bunlara bağlı olarak obstetrik komplikasyonlarla daha sik karşılaşılmaktadır. ${ }^{2,4,15}$

Adölesan gebelikler için risk faktörleri çok yönlü ve karmaşıktır. Bu risk faktörleri arasında;

\section{1-Abortus}

Dünya Sağlık Örgütü'nün epidemiyolojik tanımına göre düşük; 500 gr altında ve/veya 20 haftadan önce embriyo veya fetüsün anne rahminden ayrılmasıdır. Birçok ülkede yasalar tıbbi ve sosyal endikasyonlar nedeni ile isteğe bağlı gebeliğin sonlandırılmasına izin vermektedir. İsteğe bağlı gebeliğin sonlandırılma haftası diğer ülkelerde 12 ve 14 iken, Türkiye'de ise 1983 y1lında kabul edilen nüfus planlaması kanunu ile gebeliğin ilk on haftası boyunca isteyerek gebelik sonlandırılmasına olanak sağlamıştır. Bununla birlikte ülkemizde 10 haftadan sonraki gebeliklerde düşük uygulaması için sadece annenin yaşamının tehdit altında olması veya fetal anomali olasılığının varlığ 1 koşullarının yasalarca kabul edilmesi, kadınların üreme haklarını istenen düzeyde kullanmalarına olanak sağlamaktadır. ${ }^{17}$

Gelir düzeyi düşük olan ülkelerde 15-19 yaş arasındaki adölesanların istenmeyen gebelikleri \%14 oranında güvenli olmayan düşük ile sonuçlanmaktadır. Dünyada her yıl 2,5 milyon adölesan güvenli olmayan yollardan düşük yapmakta ve yetişkin kadınlara göre komplikasyonlardan daha fazla etkilenmektedir. ${ }^{7,16}$ Dünya Sağlık Örgütü 2006 ve 2008 verilerine göre her yıl yasal olmayan 19 milyon düşüğün 2.2 milyon ile 4 milyon arasındaki bölümünün adölesan gebelerde olduğu ve 3 milyon adölesanın güvenli olmayan kürtaj yaptırdı̆̆ bildirilmiştir. ${ }^{5,18}$ Günümüzde ise sağl1ksız koşullarda, çok tehlikeli yöntemlerle ve ehil olmayan kişiler tarafından yapılan kürtaj oranları artmaktadır. ${ }^{2,19}$

\section{2-Preterm Doğum ve Düşük Doğum A ğırlığı}

Preterm doğum eylemi, perinatal morbidite ve mortalitenin en önemli nedenidir. Adölesanlarda küçük yaş nedeni ile vücudun tam gelişmemiş olması, gebelik öncesi vücut ağırlığının düşük olması, gebelikte yetersiz kilo alma, sosyo-ekonomik düzeyin düşük olması, sigara kullanılması, anemi ve yetersiz doğum öncesi bakım erken doğumu hazırlayıc1 faktörler arasında sayılmaktadır. ${ }^{20,21} \quad$ Yapılan birçok araştırmada adölesan yaştaki gebelikler ile fetüsün düşük doğum ağırlıklı olması arasında ilişki olduğu saptanmıştır. ${ }^{22-24}$

\section{3-Preeklampsi, Eklampsi}

"International Society for the Study of Hypertension in Pregnancy (ISSHP)" ye göre hipertansiyon, gebeliğin ikinci yarısından sonra diyastolik kan basıncının $\geq 90 \mathrm{mmHg} \quad$ olmasi olarak tanımlanmaktadır. ${ }^{22,24} \quad$ Adölesanların gelişimini tamamlamadan gebe kalmaları, gebelik ile artan metabolizma, yetersiz doğum öncesi bakım, düşük sosyoekonomik düzey ve eğitim düzeyi ile birlikte, ilk gebeliklerde daha s1k 
görülmektedir. Ayrıca 20 yaş ve üzerindeki gebelere göre adölesan gebelerde preeklampsi ve eklampsi daha s1k görülmektedir. ${ }^{2,19,21}$

\section{4-Anemi}

Gelişmekte olan ülkelerde tüm gebeliklerde anemi oldukça yaygın olmakla birlikte özellikle adölesanların yaklaşık yarısı anemiktir. Adölesanların hem kendi vücutlarının hem de bebeğin büyümesinin aynı anda olması nedeniyle vücudun demir kaynakları hızla tükenmektedir. Ayrıca demir ve folik asitten yoksun beslenme ile malaria ve intestinal parazit gibi infeksiyon hastalıkları adölesan gebelerde anemi şiddetini artırmaktadır., 2,18,22,25,26 Yapılan bazı çalışmalarda adölesan gebeliklerde anemi riskinin yetişkin gebeliklere oranla daha yüksek olduğu saptanmıştır. ${ }^{3,22,24,27}$ Keskinoğlu ve arkadaşlarının 945 adölesan gebe ile yaptığı çalışmada adölesan gebelerde anemi oranını erişkin popülasyondan daha yüksek olduğunu (\%38.5) saptamışlardır. ${ }^{28}$

\section{5-Uzamış Doğum Eylemi-EMR-Aperatif Doğum-Fistül Oluşumu}

Adölesanlarda (16 yaşından küçük) pelvis gelişimi tamamlanmadığından uzamış ve ilerlemeyen doğum eylemi ilk doğumlarda çok sik görülür. Bunun nedeni genellikle küçük pelvis ya da bebeğin pozisyonunun uygun olmamasidır. ${ }^{18,29}$

Adölesan gebelerde amnion kesesi, 20 yaş ve üzerindeki gebelere göre normal doğum eylemi başlamadan önce açılmakta ve $\% 95$ oranında erken doğum eylemine ya da erken doğum riskine neden olabilmektedir. $^{2}$

Gelişmiş ve gelişmekte olan ülkelerinde sezaryen yüzdesi hizla artmaktadır. Yapılan araştırma sonuçları; adölesan gebeliklerde sezaryen riskinin arttığını gösterirken, bazı araştırmalarda sezaryen riskinin yetişkinlerden farklı olmadığı ya da daha düşük olduğunu göstermektedir. ${ }^{28,30}$ Bununla birlikte doğum müdahaleleri ise vajinal doğum sirasında çocuğun doğumunu kolaylaştırmak için yapılan forseps ve vakum uygulamalarını içermektedir. Adölesan gebelerin doğumları daha fazla müdahale edilmeyi gerektirmektedir. $^{2,30}$

Adölesan gebelerde pelvis gelişiminin devam etmesinden dolayı ve müdahaleli doğum nedeniyle fistül, idrar ve gaita inkontinansı oluşmaktadır. ${ }^{2,22,31,32}$

\section{6-Yetersiz Antenatal Bakım}

Dünya Sağlık Örgütü'ne göre gebeler gebelikleri süresince sağlı personeli tarafindan en az $4 \mathrm{kez}$ ziyaret edilmelidir. $\mathrm{Bu}$ ziyaretler 16., 24-28., 32. ve 36. gebelik haftaları arasında yapılmalıdır. ${ }^{6}$

Antenatal bakımla gebelik öncesi ve sonrası oluşabilecek birçok komplikasyon önlenebilmekte ve zamanında kontrol altına alınabilmektedir. Adölesanların gebeliğe ilişkin bilgi ve deneyimlerinin yetersiz oluşu, psikolojik durumlarının gelişmemiş olması ve duygusal durumlarının çok değişken olmasi doğum öncesi bakımın önemini bir kat daha arttırmaktadır. The Guttmacher Institute' raporuna göre her üç adölesandan biri yetersiz antenatal bakım almakta ve sağlık sorunları olan çocuklar dünyaya getirmektedirler. ${ }^{2}$

Yeterli doğum öncesi bakım alınması gebeliğin istenme durumuna bağlı değildir. Yapılan bir araştırmada gebelik istense dahi yetersiz doğum öncesi bakım alındığı tespit edilmiştir.

Araştırmalarda adölesan gebelerde oluşabilecek komplikasyonlarla yetersiz doğum öncesi bakım alma arasında güçlü bir ilişki olduğu tespit edilmiştir. ${ }^{2,33}$

\section{7-Sigara ve Keyif Verici Madde Kullanımı}

Adölesan gebelerde sigara ve kokain gibi keyif verici madde kullanımı yetişkinlere oranla daha yüksektir. Gebelikte sigara kullanımı fetal büyümenin yavaşlamasına, perinatal mortalitenin artmasina, abortusa ayrıca bebeklerin düşük doğum ağırlıklı olmasına ve erken doğum eylemine neden olmaktadır. ${ }^{21,34}$

Gebelikte kokain kullanımı gebeliğin ilk 3 ayında spontan abortusa, ikinci ve 
üçüncü aylarında erken doğum eylemine, dekolman plesanta ve erken membran rüptürüne yol açabilmektedir. ${ }^{34}$

\section{8-Kontrasepsiyon}

Evlilik öncesi cinsel deneyim ve gebelik, sosyal ve kültürel açıdan birçok ülkede kabul edilmemektedir. Evlilik öncesi cinselliğin tabu olarak görülmesi adölesanın gebelik önleyici yöntem kullanımına engel olmaktadır. Özellikle sağlık personelinin evli olmayan adölesanların aile planlaması kliniklerine başvurdukları zaman onlara ön yargılı davranması, adölesanların gerekli olan gebelik önleyici yöntemlere kolayca ulaşmalarını engellemektedir. $^{2,, 21,22}$

Beklenmedik bir zamanda planlanmadan cinsel ilişki yaşanması, gebeliği önleyici yöntemler hakkında yeterli bilgiye ve ulaşılabilirliğe sahip olunmaması, tıbbi işlemlerden korkma, ulaşım ve hizmet için gerekli ödemeyi yapamama, eşinden veya ailesinden korkma ya da çocuk sahibi olma baskısı gibi birçok faktör gebelik önleyici yöntemleri engellenmektedir. ${ }^{2,21,34}$ Yapılan bazı araştırma sonuçları adölesanların mevcut gebeliklerinden sonra ilk 24 ay içinde \%42'sinin ikinci bir istenmeyen gebelik yaşadığı ve bunların \%73'ünün doğumla sonuçlandığı tespit edilmiştir. $^{22,36}$

TNSA 2013 verilerine göre herhangi bir yöntem kullanımı 15-19 yaş grubundaki evli kadınlar arasında (\%47) en düşük düzeyde olduğu saptanmıştır.

Adölesanlar geri dönüşümsüz gebelik önleyici yöntemler hariç tüm yöntemleri kullanabilirler. Özellikle adölesanların koruyucu hormonal mekanizmaları gelişmesini tamamlamadığ bulaşan hastalıklara (HIV/AİDS) karşı daha hassas olduklarından kondom kullanmaları bu riskin oluşmasını önleyecektir. Kondomun yırtılması ya da delinmesi gibi durumlarda da acil kontrasepsiyona başvurularak gebe kalmaları engellenmelidir. ${ }^{37,38}$

Adölesanların çok büyük bir kısmı etkin olmayan gebelik önleyici yöntemleri tercih etmektedir. Etkin gebelik önleyici yöntemleri kullansalar bile yetişkinlere göre başarısız olma riskleri daha yüksektir. Bir araştırmada adölesanların \%60'nın hap almayı unuttuğu, \%50'sinin gebeliği önleyecek dozda hap almadığı ve bir bölümünün kondomun yırtıldığını fark etmedikleri tespit edilmiştir. ${ }^{38,39}$

DSÖ (2012) verileri; 20 yaş altındaki annelerin bebeklerinin, 20-29 yaş arasındaki annelerin bebeklerine oranla ilk bir haftadaki ölüm oranının \%50 daha fazla olduğu şeklindedir. ${ }^{6}$ Anne yaşı küçüldükçe bebeklerin ölüm oranının arttığını gösteren çalışmalar mevcuttur. Amerika Birleşik Devletlerinde yapılan bir çalışmada; 10-15 yaş arasındaki adölesanların bebeklerindeki ölüm riskinin \%55, 16-17 yaşındaki adölesanların bebeklerinde \%19 ve 18-19 yaş arasındaki annelerin bebeklerinde de bu oranın $\% 6$ olduğu saptanmıştır. ${ }^{16}$

Literatür bilgisi adölesan annelerin erişkin annelere oranla ilk 2 aylık dönemde bebeklerinin sorumluluğunu daha geç aldıkları ve sağlık hizmetlerine ulaşmada daha fazla sorun yaşadıklarını doğrultusundadır. ${ }^{13}$ Ayrıca adölesan annelerin çocukları, erişkin annelerin çocuklarıyla karşılaştırıldığında daha zayıf bilişsel, akademik ve davranışsal becerilere sahip oldukları, yirmi yaş altı anne çocukları otuz yaş üzeri annelerin çocuklarıyla karşılaştırıldığında, kötü sonuçlarının 1.5 ile 8.9 kat daha fazla olduğu belirlenmiştir. $\mathrm{Bu}$ çocuklarda anksiyete bozukluğu, major depresyon ve intihar girişimi, madde kullanımı ve suç işleme, eğitim başarılarında düşüklük ve okulu terk etme oranları daha fazla bulunmuştur. Aynı zamanda istismar ve ihmalde önemli risklerdir. Çocuk istismarı ve annenin ilk doğumunu yaptığ1 yaş arasında ilişki olduğu belirlenmiştir. ${ }^{8}$

Adölesan annelerin doğum sonu dönemde karşılaştıkları problemlerden biri de laktasyonun başlatılması ve sürdürülmesiyle ilgilidir. Araştırmalar anne yaşı ile emzirmenin başlatılması ve sürdürülmesi arasında önemli bir ilişki olduğu ve anne yaşı ile emzirme süresi arasında pozitif ilişki olduğunu göstermiştir. 40-48 
Özsoy'un (2014) çalışma sonuçları; daha çok istenmeyen gebelikler yaşadıkları, doğumdan sonra bebeklerini daha geç emzirdikleri, hastanede emzirme için sağlık personelinden daha az destek aldıkları saptanmıştır. ${ }^{46}$ Adölesanlara ilişkin bu sonuçlar anne yaşı ve emzirme ilişkisini göstermesi açısından anlamlıdır.

\section{Sonuç ve Öneriler}

Adölesan gebeliklerin yaygın olmasının başlıca nedenleri arasında; erken yaşta evlilikler, aile planlaması yöntemleri konusunda yetersiz bilgi sahibi olma, ulaşımdaki zorluklar, okul ve aile tarafından cinsel sağlı/ üreme sağlı̆̆ yeterli bilgilendirme yapılmamış olması, düşük sosya-ekonomik durum ve eğitim düzeyinin düşük olması gibi faktörler yer almaktadır.

Adölesan gebeliklerin önlenmesinde;

$\checkmark$ Cinsel sağlık/ üreme sağllğ hizmetlerinin adölesanlar arasında yaygınlaştırılması,

$\checkmark$ Adölesan gebelerin gidebileceği ayrı adölesan polikliniği oluşturulmas1,

$\checkmark$ Eğitim müfredatının cinsel sağlık/ üreme sağlığ1 bilgileri yönünden zenginleştirilmesi,

$\checkmark$ Gençlerin güvenli cinsel yaşam, gebelik ve ebeveyn olma ile ilgili bilgilerinin artırılmas1,

$\checkmark$ Erken gebelik nedenleri arasında yer alan; kadınların okuma ve meslek sahibi olma oranlarının düşüklüğü, kültürel ve geleneksel nedenlerin iyi değerlendirilmesi,

$\checkmark$ Adölesanlara yönelik eğitim programları hazırlanması ve kitle iletişim araçlarının etkin kullanılması önerilebilir.

\section{Kaynaklar}

1. Kütük S. Adölesan Gebelik Riskleri ve Sorunları. Türk Aile Hekimleri Dergisi 2012; 16 (Suppl):31-S34.

2. Melekoğlu. R. Adölesan Gebelikler: Maternal ve Fetal Sonuçları. Uzmanlık Tezi (2012).
3. Melekoğlu R, Evrüke C, Kafadar T, Misırlığlu S, Büyükkurt S, Özgünen TF. Adölesan Gebeliklerin Perinatal Sonuçları. Türk Jinekoloji ve Obstetrik Derneği Dergisi J( Turk Soc Obstet Gynecol) 2013; 10(4): 213- 9.

4. Sökülmez P,Özenoğlu A. Adölesan gebelerin sağlik ve beslenme durumlarının yenidoğan Sağlığı üzerine etkileri. Türk Jinekoloji ve Obstetrik Derneği Dergisi 2014;11(1): 1-9.

5. Mason E. Guidelines for preventing early pregnancy and poor reproductive outcomes Among adolescents in developing countries. Geneva, World Health Organization, 2011:1-8.

6. WHO. Early marriages, adolescent and young pregnancies. Report by the Secretariat. A 65/13. Geneva, Switzerland: WHO; 2012.

7. Dixon-Mueller R. Research issues in developing countries the sexual and reproductive health of younger adolescents WHO Document Production Services, Geneva, Switzerland. 2011: 26-9.

8. Çolak Ü. Türkiye'deki adölesan gebelikler. Eğitişim Dergisi 2012; 33(1):1-6.

9. Şen S, Kavlak O. Çocuk gelinler: Erken yaş evlilikleri ve adölesan gebeliklere yaklaşım. Aile ve Toplum Dergisi 2011; 7(25): 35-44.

10. WHO. Health-related Millennium Development Goals, Adolescent fertility rate (per 1000 girls aged 15-19 years): WHO; 2009.

11. Adölesan Doğurganlık ve Annelik. Türkiye Nüfus ve Sağlık Araştırması (TNSA) 2013: 72-73.

12. Öner S, Yapıcı G. Adölesan gebeliklere bakış. Türkiye Halk Săgll $\breve{g}_{l}$ Dergisi 2010; 8(1): 30-9.

13. Letourneau NL, Stewart M, Barnfather AK. Adolescent mothers: support needs, resources, and support-education interventions. Jounal of Adolescent Health 2004; 35(6): 509-25.

14. Cabezon C, Vigil P, Rojas I, Leiva ME, Riquelme R, Aranda W, Garcia C. 
Adolescent pregnancy prevention: an abstinence-centered randomized controlled intervention in Chilean public high school. J Adolesc Health 2005; 36(1): 64-9.

15. Y1ldirım $Y$, Ünal $M M$, Tinar $S$. Reproductive and characteristics of of adolescent pregnancies in turkish women. J Pediatr Adolesc Gynecol 2005; 18: 249-53.

16. Mangiaterra V, Pendse R, McClure K, Rosen J. Adolescent Pregnancy. MPS Notes World Health Organization 2008; 1(1):1-4.

17. Çokar M. Dünyada ve Türkiye'de isteyerek düşüğün yasal boyutunun etik açıdan değerlendirilmesi. Doktora Tezi (2006).

18. McIntyre P.Health Problems Associated With Adolescent Pregnancy. Pregnant Adolescents Delivering on Global Promises of Hope. Geneva, WHO Library Cataloguing-in-Publication Data, 2006;10-15.

19. Meydanlı MM, Çalışkan E, Ecemiş T, Arlıer S, Dölen İ, Haberal A. Adölesanlarda Gebelik sonuçlarının değerlendirilmesi. T Klin Jinekol Obst 2000; 10: 98-103.

20. Bükülmez O, Deren Ö. Perinatal outcome in adolescent pregnancies: A case-control study from a turkish university hospital. European Journal of obstetrics \& Gynecology and Reproductive Biology 2000:207-12.

21. Gökçe B, Ozsahin A, Zencir M. Determinants of adolescent pregnancy in an urban area in Turkey: a populationbased cae-control study. J Biosoc Sci 2007; 39: 301-11.

22. Demirgöz M, Canbulat N. Adölesan gebelik. Turkiye Klinikleri $\mathrm{J}$ med Sci 2008; 28(6).

23. Haldre K, Rahu K, Karro H, Rahu M. İs a poor pregnancy outcome related to young maternal age? A study of teenagers in Estonia during the period of major socio-economic changes (from 1992-2002). Eur J Obstet Gynecol Reprod Bio 2007; 131: 45-51.
24. Phupong V. Suebnukarn K. Obstetric out comes in nulliparous young adolescents. Southeast Asian J Trop Med Public Health 2007; 38: 141-5.

25. Moran VH. A systematic review of dietary assessments of pregnant adolescents in industrialised countries. Br J Nutr 2007; 97: 411-25.

26. Pathak P, Singh P, Kapil U,Raghuvanshi RS. Prevelance of iron vitamin $\mathrm{A}$, and iodine deficiencies amongst adolescent pregnant mothers. Indian J Pediatr 2003; 70: 299-301.

27. Lira Plascencia J, Oviedo Cruz H, Pereira LA, Dib Schekaiban C, Grosso Espinoza JM, Ibargüengoitia Ochoa F, et al. Analysis of the perinatal results of the first five years of the functioning of a clinic for pregnant teenagers. Ginecol Obstet Mex. 2006;74: 241-6.

28. Keskinoğlu P, Bilgiç N, Pıçakçı EM. Perinatal outcomes and risk factors of Turkish adolesccent mothers. J Pediatr Adolesc Gynecol 2007 Feb; 20(1):19-24.

29. Treffers P. Adolescent Pregnancy Issues in Adolescent Health and Development, II. Series. Geneva, WHO Library Cataloguing-in-Publication Data, 2004; 5-10.

30. Geist RR, Beyth Y, Shashar D, Beller U, Samueloff A. Perinatal outcome of teenage pregnancies in a selected group of patients. J Pediatr Adolesc Gynecol 2006; 19: 189-93.

31. Başer M. Adölesan cinselliği ve gebelik. Cumhuriyet Üniversitesi Hemşirelik Yüksekokul Dergisi 2000; 4(1).

32. Miller S, Lester F, Webster M, Cowan BObstetricfistula: A preventable tragedy. J Midwifery Womens Health 2005;50: 286-9.

33. Mahfouz AAR, El Said MM, AlErian RA, Hamid AM. Teenage pregnancy are teenagers a high risk group? European Journal of Obstetrics and Gynaecology and Reproductive

Biology 1995; 59: 17-20.

34. Covington DL, Justason BJ, Wright LN. Severity, manifestations, and 
consequences of violence among pregnant adolescents. J Adolesc Health 2000; 28: 55-61.

35. Zeck W, Bjelic-Radisic V, Haas J, Greimel E. Impact of adolescent pregnancy on the future life of young mothers in terms of social, familial, and educational changes. Journal of Adolescent Health 2007; 41: 380-8.

36. Raneri LG, Wiemann CM.Social ecological predictors of repeat adolescent pregnancy. Perspectives Sexual and Reproductive Health 2007;39: 39-47.

37. CYBE-HIV/AIDS'in Önlenmesi (2007).Gençlik Danısmanlık ve Sağlık Hizmet MerkezleriCSÜS Eğitimi Modülü, Katılımcı Rehberi. T.C.Sağlık Bakanlığı Ana Çocuk Sağlığı ve Aile Planlaması Genel Müdürlügü, Ankara; 171-204.

38. Woods JL, Shew ML, Tu W, Ofner S, Ott AM, Fortenberry DJ. Patterns of oral contraceptive pill-taking and condom use among adolescent contraceptive pill users. Journal of Adolescent Health 2006;39: 381-7.

39. Bearinger LH, Resnick MD.Dual method use in adolescents: A review and framework for research on use of STD and pregnancy protection. $J$ Adolesc Health 2003;32: 340-9

40. Alp H. Çocuklarda anne sütü ile beslenme süresi ve ilişsili faktörler. Güncel Pediatri 2009; 7: 45-52.
41. Akdolun Balkaya N, Vural G, Eroğlu K. Factors affec- ting exclusive breastfeeding in the first six weeks postpartum in Bolu, Turkey. Turkiye Klinikleri J Gynecol Obst 2009; 19(3): 142-149.

42. Dennis CL. Breastfeeding initiation and duration: A 1990-2000 literature review. JOGNN 2002; 31(1): 12-32.

43. Işık Koç G, Tezcan S. Gebelerin emzirmeye ilişkin tutumları ve emzirme tutumunu etkileyen bazı faktörler. Hacettepe Üniversitesi Hemşirelik Yüksekokulu Dergisi 2005: 1-13.

44. McKechnie AC, Tluczek A, Henriques, JB. Maternal variables influencing duration of breastfeeding among lowincome mothers. ICAN: Infant, Child \& Adolescent Nutrition 2009; 1(3): 125132.

45. Santo ACE, Oliveira LD, Giugliani ER. Factors associated with low incidence of exclusive breastfeeding for the first 6 months. J BIRTH 2007; 34(3): 212-219.

46. Thulier D, Mercer J. Variables associated with breastfeeding duration. JOGNN 2009, 38: 259-268.

47. Özsoy S. Adölesan annelerin emzirmeye yönelik düşünce ve uygulamaları. F.N.Hem. Derg. 2014;22(2):84-93.

48. Yıldız H, Küçükşahin N. Kırsal bölgede annelerin doğum sonu yaşadıkları sorunlar ve bakım gereksinimleri. Türk Aile Hek Derg.2011; 15(4): 159-166. 